\title{
Knowledge Productivity in the 2020s: Time for a New E/RA A Research Study on the Impact of Organizational Design and Employee Engagement on the Knowledge Productivity of Service Firms
}

\author{
Bas Kodden \\ Nyenrode Business University \\ Ramon van Ingen \\ Nyenrode Business University
}

\begin{abstract}
The subject of this study is the interdisciplinary perspective approach to knowledge productivity within the service industry. Relationships between organizational design and employee engagement are studied between constructs of both organizational and psychological theory and their effects on knowledge productivity, whereby an attempt is made to bridge both disciplines. Amongst other things the level of responsible autonomy $(R A)$ is related to employee engagement (E) and organizational knowledge productivity. It is argued that an organizational design and the "misfit" of the employee's preferences with the perceived organizational design characteristics will have a strong negative influence on their work engagement- and knowledge productivity levels.
\end{abstract}

Keywords: Organizational Design, Employee Engagement, Knowledge Productivity, Knowledge Service Firms.

\section{INTRODUCTION}

The success of organizations with many knowledge workers, such as law firms, insurance companies and accounting firms, is assumed to be depending on the quality, performance and engagement of the knowledge workers themselves (Davenport, 2005; Davenport \& Prusak, 2000; Drucker, 1999; Maister, 1999; Mayson, 1997; Mintzberg, 1998; Maister, 1999). To quote Davenport (2005): "In the current economy, they are the horses that pull the plow of economic progress. If our companies are going to be more profitable, if our strategies are going to be successful, it will be because our knowledge workers did their work in a more productive and efficient manner." But how can organizations be successful in engaging and retaining their knowledge workers and avoid the risk of attrition of their best employees? And in what manner can they increase productivity by improving internal and external knowledge sharing?

Many policymakers grew up with the idea that economies of scale lead to lower costs, which is understandable as this was accepted for hundreds of years. In the agricultural and industrial economy, economies of scale were necessary to produce at lower costs but in the modern service economy this 
relationship no longer exists. Leaders of service firms also realize that recruiting, retaining and developing talented employees is crucial for the competitive power of their firms. We define service firms as organizations that provide mainly knowledge, information and other services to their clients. However, has the traditional organizational design of service firms meanwhile also been adjusted to modern times and to today's knowledge worker's preferences? Regrettably, we have to conclude that the organizational design of many service firms is still based on classic, bureaucratic, organizational design principles and characterized by a hierarchical, functional structure and jobs with low levels of responsible autonomy (De Sitter, 2000; De Sitter, den Hertog, \& Dankbaar, 1997; Kodden, 2011; Kuipers \& Van Amelsvoort, 1990; Kuipers, Van Amelsvoort, \& Kramer, 2010). The consequences of this are: disengagement of the labor force and a high attrition of well-educated, incorporated knowledge workers. According to Kuipers et al. (2010), it is even structurally impossible to motivate highly-educated individuals in such environments.

This paper addresses the influence of organizational design on employee engagement from a perspective of structures in the division of labor. We will present MSTS as a diagnostic theory and as a design theory. We thereby define MSTS as an integral theory of organizational performances in relation to their environmental context, which is determined by the mutual connection of organizational design, in terms of structure and systems (the technical instrumentation), and the social variables (attributes of people and mutual relations). According to this definition of MSTS, organizational design is seen as a strategic issue. Explaining, designing and changing organizations takes places in relation to the environmental conditions and strategic choices and gives direction to the required organizational design. This organizational design determines the results obtained in the areas of quality of the organization, quality of labor and quality of labor relationships and the organization is seen as an integrated cohesion of both social and technical variables.

This study tries to build a bridge between organizational and psychological theories as the impact of engagement on knowledge productivity within this study is addressed by the definition given by Schaufeli and Bakker (2004); A positive state of mind of overwhelming satisfaction which is being characterized by vitality, dedication and absorption, and the study's view on knowledge productivity is from a perspective of organizational design. Therefore, both psychological as well as organizational theories apply to this study. The relevance of interdisciplinary research within management literature is pointed out frequently, for example in a discussion in the British Academy of Management: "Management research cannot be reduced to any sum of parts framed in terms of contribution to associated disciplines" (Tranfield \& Starkey, 1998).

The main research question is as follows:

\section{What are the effects of organizational design and employee engagement on knowledge} productivity within service firms?

This paper's definition of employee engagement is analogous to the definition of work engagement by Bakker (2009). Vitality refers to a state of mind in which man feels very energetic, fit, strong and tireless, dedication refers to a state of mind in which man feels very engaged by his work, which is inspiring and man feels proud and enthusiastic about, and absorption refers to a pleasant state of mind in which man is fully immersed in work." Earlier studies using this definition of work engagement are limited, but promising (Bakker, 2009). The study has four objectives:

1. to identify and to analyze the use of the functional organizational design plus the levels of work engagement and knowledge productivity within different sectors of the knowledge service industry;

2. to identify the directions and strengths of relationships of the variables used within the conceptual model, using statistical analyses techniques;

3. to identify causal relationships between the variables using correlation and regression analyzing techniques;

4. to create an explanatory model for service firms that helps to improve their knowledge productivity in the organization. 
This article is divided into five sections. In the first section we will define six hypotheses, which reflect the theory that are used to investigate the relations between the organizational design, work engagement and knowledge productivity. In the second section we will describe the methods and measures to test the hypotheses. Empirical results are presented in the third section. The fourth section presents the conclusions, discussion and suggestions for practice. Finally, the fifth section describes the limitations of this study and suggestion for further research.

\section{HYPOTHESES}

As previously outlined, studying the influence of organizational design on knowledge productivity in this paper is addressed from a perspective of structures in the division of labor. Various studies in recent decades prove that many organizations of today are still designed by Tayloristic principles (Taylor, 1911), where the organizational design contains a high division of labor and high levels of organizational structures (De Sitter, 2000; Kuipers et al., 2010). The design of an organization reflects the value-based choices made by the company; it refers to how job tasks are formally divided, grouped and coordinated and how job characteristics are perceived. A hierarchical, functional design is thereby characterized by high levels of division of labor and organizational structures, while work is divided into specialist teams. Below we will address division of labor "as the level at which the organizational design breaks action, job or task into small and simple segments which can be easily analysed and taught." Division of labor aims to achieve maximum job fragmentation to minimize skill requirements and job learning time, separates execution of work from work planning and separates direct labor from indirect labor.

Clustering activities to, for example, teams of specialist and dividing labor lead to less of internal and external responsible autonomy for workers as the level of the division in labor determines the position of power: a high level of division in labor gives managers the monopoly of insight and overview and gives them greater powers to command and control (De Sitter, 2000; Kuipers et al., 2010). Levels of flexibility and innovation decrease under these circumstances (Cross \& Parker, 2004; Van Amelsvoort, 1999; Williams, 2005). The MSTS strongly emphasizes the importance of the level in the division of labor and responsible autonomy for the elements of employee engagement (Kuipers et al., 2010; Pasmore, 2010).

In jobs with a lack of responsible autonomy, the employee (or group of employees) is being cut off from the purpose and meaningfulness of the organizational existence (De Sitter, 2000; De Sitter et al., 1997; Kuipers \& Van Amelsvoort, 1990; Kuipers et al., 2010). Internal responsible autonomy is important for solving the problems of daily practice (how the work is done).

External responsible autonomy is important to determine what work has to be done. In case of a structural absence of responsible autonomy a stress situation is created (Kuipers et al., 2010). The wellknown stress studies of Karasek (2001) and Karasek and Theorell (1990) supports the idea of a relationship between responsible autonomy and the perception of stress by an employee. Stress is not caused by the problems at work themselves, but by the lack of possibilities to solve them. In line with the MSTS and the studies of Karasek (2001) and Karasek and Theorell (1990) we assume that the functional organizational design, characterized by a high division of labor into teams of specialists, results in low levels of responsible autonomy (RA) for employees and is of negative influence on the engagement levels (E) of knowledge workers.

Employee engagement is generally viewed as managing discretionary effort, that is, when employees have choices, they will act in a way that furthers their organization's interests. An engaged worker is a person who is fully involved in, and enthusiastic about, his or her work. In 2008, Bakker and Schaufeli introduced the emerging concept of work engagement in their position paper, Work engagement: An emerging concept in occupational health psychology (in Work \& Stress Vol. 22, No. 3, July-September 2008, 187-200). They defined work engagement as a positive, fulfilling, affective-motivational state of work-related well-being that is characterized by vitality, dedication, and absorption. That is, in engagement, fulfilment exists in contrast to the voids of life that leave people feeling empty, such as in burnout. Vitality is characterized by high levels of energy and mental resilience while working, the willingness to invest effort in one's work, and persistence even in the face of difficulties. Dedication 
refers to being strongly involved in one's work, and experiencing a sense of significance, enthusiasm, inspiration, pride and challenge. Absorption is characterized by being fully concentrated and happily engrossed in one's work, whereby time passes quickly and one has difficulties with detaching oneself from work. Employees who are working in an organization with a functional design, where labor is highly divided into specialized teams and jobs contain low levels of responsible autonomy, will then negatively respond to the elements of work engagement.

Hypothesis 1: Within the services industry, vitality, dedication and absorption levels of employees will be negatively related to the functional organizational design.

In this study we assume that the functional organizational design within knowledge intensive firms is negatively related to the level of work engagement and knowledge productivity as the knowledge worker perceives a "misfit" between his preferred and perceived organizational design characteristics. According to the Person-Environment theory (Cable \& Parsons, 1997; Edwards, 1991; Kristof, 1996; Taris, 2003) we assume that if the employee's preferences do not fit the perceived organizational design characteristics, results will not occur. According to Dullaert, Griendt, and Van De (2004), knowledge professionals such as legal workers prefer a high level of autonomy, responsibility and freedom, which does not seem to fit the results of the functional organizational design as described in the MSTS (De Sitter, 2000; De Sitter et al., 1997; Kuipers \& Van Amelsvoort, 1990; Kuipers et al., 2010).

\section{Hypothesis 2: A Person-Organizational Design misfit will be positively related to the functional organizational design.}

The functional organizational design does not necessarily indicate a Person-Organizational Design (POD) misfit. The employees' preferences may actually correspond with the characteristics of the functional organizational design. And a P-OD misfit can also occur in companies that do not have a functional organizational design, if this organizational design does not fit the personal preferences of that employee. In our study, the factor of P-OD (mis)fit is therefore used as an autonomous factor to analyze the effects of organizational design on the vitality, dedication and absorption of employees.

\section{Hypothesis 3: Work engagement will be negatively related with P-OD misfit.}

The main outcome studied in this article concerns the knowledge productivity of service organizations. We define knowledge productivity as the result of organizational knowledge sharing, the discretionary effort made by skilled and motivated employees to serve their clients and a more or less longer duration of stay by these professionals at their firms (Heskett, Sasser, \& Schlesinger, 1997). Knowledge sharing is then defined as an organization's capacity to save time by leveraging the firm's knowledge resources (cf. Eisenhardt \& Tabrizi, 1995; Hansen, 1999), to enhance work quality as a result of utilizing knowledge (cf. Cummings, 2004; Haas, 2006; Levin, 2000), and the ability to signal competence to external constituencies as a result of leveraging knowledge (cf. McEvily, Das, \& McCabe, 2000; Podolny, 1994).

Previous studies of work engagement by Bakker, Demerouti, and Verbeke (2004) demonstrated that engaged employees do whatever they are asked to do and are more than willing to help their colleagues. Also in other countries a relationship between work engagement and results was found. A study of Halbesleben and Wheeler (2008) in America showed that work engagement is a good predictor of results, independent of the source of information (employee, managers and colleagues), as a study of Salanova, Agut, and Peiró (2005) in Spain proved that work engagement has predictive value for the service willingness and results of employees. According to Bakker (2009) there are four reasons why engaged employees perform better than disengaged employees. Employees with a high level of work engagement 1) experience positive emotions; 2) experience a better health; 3) create their own work-related and personal resources; and 4) also inspire others to become engaged. 
Hypothesis 4: In the knowledge services industry, knowledge productivity will be positively related to the vitality, dedication and absorption levels of knowledge workers.

The main assumption made in this study is that knowledge workers, who are employed in organizations with a functional design, where labor is highly divided into specialized teams and jobs contain low levels of responsible autonomy (RA), are less engaged (E) and will respond negatively to the elements of knowledge productivity, as the functional organizational design characteristics do not fit their preferences (Taris, 2003; Williams, 2005). The last hypotheses are therefore:

Hypothesis 5: Knowledge productivity will be negatively related with P-OD misfit.

Hypothesis 6: Within the knowledge services industry, knowledge productivity of employees will be negatively related to functional organizational design.

To be able to test these six hypotheses and research to what extent the organizational design influences the levels of P-OD misfit, work engagement and knowledge productivity, we use the following explanatory model (FIGURE 1).

FIGURE 1

EXPLANATORY MODEL

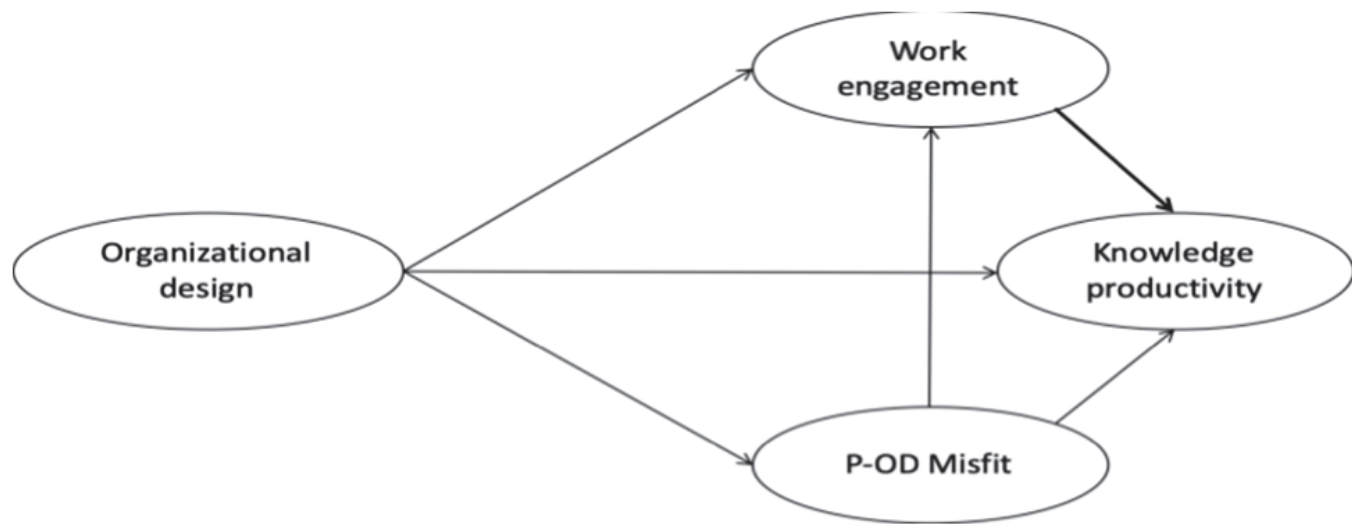

\section{METHOD}

\section{Sampling}

In this study, we collected data using a survey approach with the help of a structured questionnaire with direct questions. The knowledge workers were selected from a large database of approximately 15.000 employees within the Dutch legal, financial and business services industry. To test for quality, we pre-tested the questionnaire on 100 Dutch knowledge workers. The results were found to be satisfactory. Since the main objective of this research was to find interrelationships between organizational design characteristics and knowledge productivity within different sectors of the Dutch services industry, a nonproportional, quota sampling technique was found to be adequate for this study, as it met our sampling objectives satisfactorily (Blumberg, 2005, p. 220). In this study, 300 employees within three sectors of the Dutch services industry and two types of organizations are compared to each other. We therefore selected and divided a sample of 300 knowledge workers operating within three sectors of the Dutch services industry and employed in firms operating with more than 30 and the others with less than 30 knowledge workers (all groups: $\mathrm{N}=50$ ):

-G1: Fifty Dutch knowledge workers within large(r) legal services firms and

-G2: Fifty Dutch knowledge workers within small legal services firms;

-G3: Fifty Dutch knowledge workers within large(r) financial services firms and 
-G4: Fifty Dutch knowledge workers within small financial services firms;

-G5: Fifty Dutch knowledge workers within large(r) business services firms and

-G6: Fifty Dutch knowledge workers within small business services firms.

The main reason for this grouping is to find out what differences in organizational design can be found between these sub-groups and which sub-group faces which problems with effective engagement and knowledge productivity.

\section{Data Analysis}

To identify the directions and strengths of relationships of the variables used within our explanatory model, correlation analyses techniques are used. Multivariate analysis of variance (MANOVA) are then used to test whether there are significant differences in scores between the three services sectors and the different sizes of organizations. Hierarchical stepwise regression analyses are finally used to examine which variable is most important in explaining work engagement and knowledge productivity for both the total group of respondents and for the three service sectors separately.

\section{Measures}

The measurement instruments used in this study are based on organizational and psychological theories. Most of the questions used were derived from valid tests, for example the UBES (Schaufeli \& Bakker, 2004). To verify if the data was suitable for factor analysis, we first checked the Kaiser-MeyerOlkin Measure of Sampling Adequacy (KMO value), which was found to be satisfactory (0.8). The Bartlett's Test of Sphericity was found to be significant $(p=0.000)$. Cronbach's Alpha of all factors had a value of at least 0.6 which is considered to be a reasonable indication of sufficiently reliability.

With the help of a 7-point Likert scale (totally agree $=6$, totally disagree $=0$ ), three questions were used to measure the two items of organizational design, i.e. the level of division of labor and the level of the organizational structures. The first two questions considered the level of division of labor and the assumed high scores of functional designs within larger service firms. Within the functional organizational design structure, workers or specialists from the same discipline are brought together, and work is strongly divided into these specialized teams. The first two questions were meant to measure the degree in the division of labor while question 3 was meant to measure the degree of the perceived level of structures within the organization: "within our organization, employees are strongly divided into specialized departments"; "within our organization, work is strongly divided into these specialized departments" (answer categories: $0=$ completely disagree, to $6=$ completely agree). Average scores on these questions above 4.50 indicated a (very) high level, while an average score below 3.00 indicated a (very) low level in the division of labor and a (very) low level of organizational structures.

Schaufeli and Bakker (2004) created a valid questionnaire for the applied definition of work engagement: a positive state of mind of overwhelming satisfaction which is being characterized by vitality, dedication and absorption, which questionnaire is used in this research (the UBES-15). With the help of another 7-point Likert scale (always/daily $=6$, never $=0$ ), five questions for the three items were used to measure the level of vitality, dedication and absorption.

Answers to questions such as "At work I feel fit and strong," should then indicate the level of vitality, while questions such as "My work inspires me" and "Time flies when I am working" indicated respectively the level of dedication and absorption.

To measure knowledge productivity, we asked the knowledge workers to respond to statements about the five items of the applied definition of knowledge productivity: time savings, quality of work, signal of competencies, making discretionary effort and the intention to have a longer duration of stay at their firms. To capture the extent to which a knowledge worker managed to save time by using knowledge from other parts of the firm, we asked for example the following question: "I am able to spend much less time on my counsels because we save all the existing knowledge in the databases of our firm" (answer categories for time savings range from $0=$ completely disagree, to $6=$ completely agree). Then the knowledge workers were asked to assess the quality of the advice delivered by their services firm by responding to statements such as: "The overall advice within this firm (analyses, solutions, presentations 
and documentations) is among the best I have ever seen" (answer categories for quality of work range from $0=$ completely disagree, to $6=$ completely agree). The theory of organizational knowledge sharing further suggest that the ability to signal competence to a prospective client by communicating the firm's distinctive strengths is another important aspect of task performance, and that this ability does not depend entirely on the quality of the advice itself. The knowledge workers were asked to respond to statements such as: "I am able to communicate the firm's unique competencies in the areas of advice to the client" (answer categories for signal of competencies range from $0=$ completely disagree, to $6=$ completely agree). On the question: "The voluntary effort I spend lies above the minimum level of effort required in order to keep my job and is directed toward organizational goals," average scores above 4.50 indicated a (very) high level of discretionary effort and average scores below 3.00 a (very) low level. The same goes for the answer to the question whether the employee had the intention to stay for at least another 24 months at his firm. To measure the level of knowledge productivity, an average score above 4.50 indicated a (very) high level of organizational knowledge productivity and average scores below 3.00 a (very) low level (7-point scale from $1=$ do not agree, to $7=$ fully agree). In addition to common individual level (e.g. gender, age group, contract status, job experience and length of labor contract) and organizational level control factors (e.g. size and type of organization), we used possible contingency factors (e.g. environmental uncertainty) as additional control variables in this study.

Following recommendations made by Podsakoff and colleagues (2003), several steps are taken to minimize the effects of common method bias in this study. First, we carefully constructed the items. By defining unfamiliar terms, avoiding vague concepts, and keeping questions simple, specific and concise, we reduced item ambiguity. Second, we separated the variables of interest in the questionnaire to create the appearance that the measure for organizational design was not related either to the mediating variables or to the dependent variables of work engagement and knowledge productivity. This helps reduce biases in the response by making a prior response less salient, available or relevant. Third, respondents were assured of complete confidentiality and encouraged to answer the questions as honest as possible. This was done to help reduce any evaluation apprehension and make them less likely to provide socially desirable responses. Fourth, Harman's Single Factor Test was performed.

Although the chances of socially desirable responses cannot be excluded, this factor does not appear to be a serious threat in this study, as the results are in fact in line with studies on work engagement and its effects on organizational results (Bakker, Demerouti, \& Verbeke, 2004; Salanova, Agut, \& Peiró, 2005; Schaufeli, 2003; Van Rhenen, 2010). With the potential for social desirability and same-source bias, given the procedural steps taken to reduce the threat of bias, the results of Harman's Single Factor Test appear to indicate that common method variance is not a serious threat in this study.

\section{RESULTS}

To test whether there are significant differences in scores between the three services sectors and the sizes of the organizations one-way multivariate analysis of variance are conducted (MANOVA). 
TABLE 1

MANOVA (MULTIVARIATE ANALYSIS OF VARIANCE)

\begin{tabular}{|c|c|c|c|c|c|c|c|}
\hline & Effect & Value & $\mathrm{F}$ & Hypothesis & Error df & Sig. & $\begin{array}{c}\text { Partial } \\
\text { Eta }\end{array}$ \\
\hline Intercept & Pillai's Trace & ,992 & $12676,946^{\mathrm{a}}$ & 3,000 & 292,000 &, 000 & ,992 \\
\hline & Wilks' Lambda &, 008 & $12676,946^{\mathrm{a}}$ & 3,000 & 292,000 &, 000 & ,992 \\
\hline & Hotelling's Trace & 130,243 & $12676,946^{\mathrm{a}}$ & 3,000 & 292,000 &, 000 & ,992 \\
\hline & Roy's Largest Root & 130,243 & $12676,946^{\mathrm{a}}$ & 3,000 & 292,000 &, 000 & ,992 \\
\hline Sector & Pillai's Trace &, 057 & 2,847 & 6,000 & 586,000 &, 010 &, 028 \\
\hline & Wilks' Lambda & ,944 & $2,842^{\mathrm{a}}$ & 6,000 & 584,000 &, 010 &, 028 \\
\hline & Hotelling's Trace &, 059 & 2,837 & 6,000 & 582,000 &, 010 &, 028 \\
\hline & Roy's Largest Root &, 040 & $3,861^{\mathrm{b}}$ & 3,000 & 293,000 &, 010 &, 038 \\
\hline Size & Pillai's Trace & ,364 & $55,610^{\mathrm{a}}$ & 3,000 & 292,000 &, 000 & ,364 \\
\hline & Wilks' Lambda &, 636 & $55,610^{\mathrm{a}}$ & 3,000 & 292,000 &, 000 & ,364 \\
\hline & Hotelling's Trace &, 571 & $55,610^{\mathrm{a}}$ & 3,000 & 292,000 &, 000 & ,364 \\
\hline & Roy's Largest Root &, 571 & $55,610^{\mathrm{a}}$ & 3,000 & 292,000 &, 000 & ,364 \\
\hline Sector * & Pillai's Trace &, 110 & 5,672 & 6,000 & 586,000 &, 000 &, 055 \\
\hline Size & Wilks' Lambda &, 891 & $5,784^{\mathrm{a}}$ & 6,000 & 584,000 &, 000 &, 056 \\
\hline & Hotelling's Trace &, 122 & 5,895 & 6,000 & 582,000 &, 000 &, 057 \\
\hline & Roy's Largest Root &, 114 & $11,157^{\mathrm{b}}$ & 3,000 & 293,000 &, 000 & , 103 \\
\hline
\end{tabular}

a. Exact statistic

b. The statistic is an upper bound on $\mathrm{F}$ that yields a lower bound on the significance level.

c. Design: Intercept + Sector + Size + Sector $*$ Size

Dependent variables: OD, WE and KP. Fixed factors: Size and Sector

These first explorative findings (TABLE 1) demonstrate that employees working in larger service firms (G1) have the highest scores on the perceived level of functional organizational design plus the level of P-OD misfit and one of the lowest on knowledge productivity. Employees working in all of the smaller firms (G2, G4 and G6) have lower scores on the perceived level of functional design than their counterparts within larger firms and score better results on work engagement and knowledge productivity, which implies that they feel and also perform better than their colleagues in larger firms. The results from the multivariate analysis of variance confirm that significant differences in organizational design, work engagement and knowledge productivity can be found between the sizes of organization. Significant differences are not found between the three sectors within the service industry (at 0.05-level). Pearson correlation analysis is then performed to determine the strength and direction of the linear relationship between the factor items used. 
TABLE 2

MEANS, STANDARD DEVIATIONS AND CORRELATIONS AMONG STUDY VARIABLES

\begin{tabular}{|c|c|c|c|c|c|c|c|c|c|c|c|c|}
\hline & Mean & $\begin{array}{l}\text { Standard } \\
\text { deviation }\end{array}$ & 1. & 2. & 3. & 4. & 5. & 6. & 7. & 8. & 9. & 10. \\
\hline 1. Division of labor & 3.84 & 1.23 & & & & & & & & & & \\
\hline 2. L. of structures & 3.95 & 0.99 &, $392 * *$ & & & & & & & & & \\
\hline 3. P-OD misfit & 2.81 & 1.25 &, $419 * *$ &, $225^{* *}$ & & & & & & & & \\
\hline 4. Vitality & 4.46 & 0.64 & , $358 * *$ & , $244 * *$ & $-\overline{347 * *}$ & & & & & & & \\
\hline 5. Dedication & 4.40 & 0.67 &, $305 * *$ & $234 * *$ & , $342 * *$ &, $701 * *$ & & & & & & \\
\hline 6. Absorption & 4.18 & 0.62 & $-376 * *$ & - $293 * *$ & - $424 * *$ &, $685^{* *}$ &, $720 * *$ & & & & & \\
\hline 7. Time savings & 3.75 & 0.84 &, 086 &, $206 * *$ &, 060 & ,058 &, $142 *$ & ,039 & & & & \\
\hline 8. Quality of work & 4.08 & 0.78 &,- 077 & 055 &,- 058 &, $254 * *$ & ,293** &, $255^{* *}$ &, $354 * *$ & & & \\
\hline 9. Signal of comp. & 4.13 & 0.98 & ,037 &,- 004 &,- 029 &, $364 * *$ &, $347^{* *}$ &, $239 * *$ & $200^{* *}$ &, $289 * *$ & & \\
\hline 10. Discr. effort & 3.45 & 0.95 & - $398 * *$ & - $313 * *$ & - $272 * *$ & ,261** &, $378^{* *}$ & ,376** & ,017 &, $141^{*}$ &, $188^{* *}$ & \\
\hline 11. Durance of stay & 3.93 & 1.55 & $355^{* * *}$ & - $192 * *$ & $398 * *$ & $419 * *$ &, $514 * *$ & $472 * *$ &, $141^{*}$ & $292 * *$ & $203 * *$ &, 519 \\
\hline
\end{tabular}

$* *: p<.01 ; *: p<.05$

TABLE 2 shows that all used items are significantly correlated at 0.05 -level except for the factor items:

1) time savings: no significant correlation was found with division of labor, P-OD misfit, vitality, absorption and discretionary effort;

2) quality of work: no significant correlation was found with division of labor, level of structures and P-OD misfit.

3) signal of competence: no significant correlation was found with division of labor, level of structures and P-OD misfit.

To study the influence of individual and organizational control factors on work engagement and knowledge productivity, hierarchical stepwise multiple regression analyses are conducted to examine which variable explain the most variance in the work engagement of employees and the knowledge productivity of the service firm. To control the effects of individual and organizational aspects, step 1 of the analyses included gender, age, level of education, contract status, position, years of work experience, years of function experience, years of organizational experience, sector and size of the firm. Next, in step 2 , first the independent factor (items) of organizational design was added to the regression model, and in Step 3 the other factors (items) of the model were included. In order to explore possible interactions between the factors, all factors (items) were added to the regression model in step 4. The significant results (sig. $<0.05)$ for each step are shown in the TABLES 3 and 4. 
TABLE 3

HIERARCHICAL REGRESSION ANALYSES TO EXPLAIN THE KNOWLEDGE PRODUCTIVITY FOR THE TOTAL GROUP AND EACH SECTOR

\begin{tabular}{|c|c|c|c|c|}
\hline & $\begin{array}{c}\text { Total group } \\
\beta \\
\end{array}$ & $\begin{array}{c}\text { Legal sector } \\
\beta\end{array}$ & $\begin{array}{c}\text { Financial } \\
\text { sector } \\
\beta\end{array}$ & $\begin{array}{c}\text { Business } \\
\text { sector } \\
\beta\end{array}$ \\
\hline $\begin{array}{l}\text { Step } 1 \\
\text { Size organization }\end{array}$ & 0.185 &, 340 &, 312 & \\
\hline $\begin{array}{l}\text { Step } 2 \\
\text { Size organization } \\
\text { Division of labor }\end{array}$ & $\begin{array}{r}0.118 \\
-0.091 \\
\end{array}$ &,- 345 & ,289 & \\
\hline $\begin{array}{l}\text { Step } 3 \\
\text { Size organization } \\
\text { Division of labor } \\
\text { P-OD Misfit } \\
\text { Dedication }\end{array}$ &, 532 & $\begin{array}{l}-, 179 \\
, 494\end{array}$ & $\begin{array}{l}, 184 \\
, 141 \\
, 554\end{array}$ & ,544 \\
\hline $\begin{array}{l}\text { Regression model } \\
\text { Explained Variance R2 } \\
\text { Adjusted R2 }\end{array}$ & $\begin{array}{l}38,4 \% \\
33,7 \%\end{array}$ & $\begin{array}{l}52,8 \% \\
40,8 \% \\
\end{array}$ & $\begin{array}{l}59,8 \% \\
49,6 \% \\
\end{array}$ & $\begin{array}{l}48,1 \% \\
35,0 \% \\
\end{array}$ \\
\hline
\end{tabular}

Note: Values are standardized regression coefficients ( $\beta$ ) of the final model of $t$, except for the Regression model where rows represent $R 2$ values

As the factor item "dedication" proves to be such an important predictor for the level of knowledge productivity of a PSF, explaining between $29,4 \%$ and $44,8 \%$ of the variance, a stepwise regression analysis on this single factor item was conducted to analyze which factor items then turn out to exert the strongest influence on the dedication levels of employees.

TABLE 4

HIERARCHICAL REGRESSION ANALYSES TO EXPLAIN THE LEVELS OF DEDICATION FOR THE TOTAL GROUP AND EACH SECTOR

\begin{tabular}{|l|c|c|c|c|}
\hline & $\begin{array}{c}\text { Total } \\
\text { group } \\
\beta\end{array}$ & $\begin{array}{c}\text { Legal sector } \\
\beta\end{array}$ & $\begin{array}{c}\text { Financial } \\
\text { sector } \\
\beta\end{array}$ & $\begin{array}{c}\text { Business } \\
\text { sector } \\
\beta\end{array}$ \\
\hline $\begin{array}{l}\text { Step 1 } \\
\text { Size organization }\end{array}$ & 0.397 &, 441 &, 295 &, 210 \\
\hline Step 2 & 0,212 & &, 305 &, 164 \\
Size organization & $-0,087$ &,- 271 & & \\
Division of labor & & & &, 169 \\
\hline Step 3 & &,- 219 & &,- 116 \\
Size organization & -0.121 &,- 128 &,- 181 & \\
Division of labor & &,- 166 &, 272 & \\
P-OD misfit & & & & \\
Task Autonomy & $21.3 \%$ & $42,5 \%$ & $30,2 \%$ & $24,8 \%$ \\
\hline Regression model & $16.3 \%$ & $30,6 \%$ & $15,8 \%$ & $9,2 \%$ \\
Explained Variance R2 & & & \\
Adjusted R2 &
\end{tabular}

Note: Values are standardized regression coefficients ( $\beta$ ) of the final model of $t$, except for the Regression model where rows represent $R 2$ values 


\section{CONCLUSIONS, DISCUSSION AND SUGGESTIONS FOR PRACTICE}

The aim of this study was to gain insights into the effects of responsible autonomy and employee engagement on knowledge productivity. Two assumptions were the starting point of this research:

a. The organizational design of large(r) service firms is highly functional, characterized by a high division of labor and a high level of organizational structures, which results in a decreased level of responsible autonomy for the workers.

b. In contradiction with this organizational design, knowledge workers have a high appreciation for work aspects such as task autonomy, task variety and responsibility resulting in a PersonOrganizational Design misfit, which itself is negatively related to the work engagement of employees.

Knowledge productivity, as the dependent variable in this study, is found to be quite predictable. Firstly, the results from the correlation and stepwise regression analyses confirm that the size of the company, organizational design, P-OD misfit and engagement levels significantly influence the knowledge productivity of knowledge workers. Secondly, the knowledge productivity of a service firm seems to be most strongly influenced by the dedication levels of its knowledge workers. This item explains $38 \%$ of the variance in knowledge productivity for the total group. TABLE 2 demonstrates that the level of dedication of an employee is strongly related to the levels of P-OD misfit and task autonomy as perceived by the employee. This will result in a decrease in the willingness of employees to make a discretionary effort towards organizational goals and an increased chance that employees will leave their firms and change employer, taking organizational knowledge with them.

Finally, a number of factors, which are often mentioned in literature or practice as being important for work engagement or knowledge productivity, were not considered to be important in this study. The factor of knowledge sharing, the organizational capacity to share knowledge efficiently among individuals and teams, was not found to have a relevant role in the relationships between organizational design, work engagement and knowledge productivity. This conclusion is in contradiction with the results of previous studies. According to the MSTS theory (De Sitter, 2000; De Sitter, 1997; Kuipers \& Van Amelsvoort, 1990; Kuipers et al., 2010), the level of knowledge sharing decreases when the division of labor is increased. As the number of relationships or interfaces grows exponentially with the level of division of labor, it increases the chances of disturbances, delays and misunderstandings in the information transfer (Kuipers et al., 2010). A possible reason for the different interpretations may be the definition of knowledge sharing used in this study: although quality of work is a well-used term in the MSTS theory, we did not find studies where efficient knowledge sharing is defined as the saving of time and means through optimal use of available organizational knowledge resources (Eisenhardt \& Tabrizi, 1995; Hansen, 1999) and the employees' skills to better signal their organization's competences towards clients (McEvily, Das, \& McCabe, 2000; Podolny, 1994). A more methodical cause can be that the measurement of the factor knowledge sharing in this study took place at the same source, thereby causing a risk of common source variance.

The size of the organization, which is being used as a control factor in this study, is not found to have a significant influence on the elements of effective knowledge sharing. Apparently, employees who are working in smaller and larger service firms are equally capable of signaling their organization's competence. Also, both types of organizations are apparently equally capable of efficiently sharing organizational knowledge and saving time and means by, for example, using advanced databases. This last argument, time savings, is often used by policymakers of larger firms to defend the functional organizational design. As smaller service firms have an organizational design that is by nature less functional, giving more autonomy and responsibility to their knowledge workers, they have a higher level of work engagement and knowledge productivity at their disposal. In order to compete successfully with their small competitors, larger service firms must adjust their organizational design to one that gives more task autonomy, task variety and responsibility to their employees

Since the mid-1990s, a well thought out and sustainable alternative for the classical, bureaucratic design principles has been developed and tested for success (De Sitter, 2000; Kuipers et al, 2010, 
Pasmore, 2010). This perspective, the integral design approach, offers structural solutions for the limitations and dysfunctions of the functional organizational design. The integral design is however not a panacea that solves every problem within organizations, but offers a sustainable framework of issues of flexibility, innovation, value-adding and quality of work (Kuipers et al., 2010). The MSTS is often associated with humanizing and democratizing of the workplace and with self-directed work teams. Although there is nothing wrong with humanizing the workplace and creating self-directed work teams, the integral design approach occupies the central place within the MSTS: the strategy of the organization is leading, whereby the primary process and demands are the starting point for redesigning the organization. Our study shows that service firms who want to keep their employees engaged and productive should choose for an integral design approach which leaves room for more responsibility, autonomy and freedom for their knowledge workers and does not highly divide their daily work.

\section{LIMITATIONS AND SUGGESTIONS FOR FURTHER RESEARCH}

Studying a subject intensively tends to lead to more, rather than fewer questions. Some of the research questions that have emerged during the course of this study are a result of clear limitations of the empirical work conducted, whereas others result from the newly acquired insights themselves. Scholars always seem to prefer more data to less data in their empirical studies. We are no different. We would have liked to include and to use more data on daily practices of service firms, and to have conducted more interviews and within more sectors of the services industry. A broadening of this study to the services industry of other countries seems interesting and is our main suggestion for subsequent studies.

In this study we have chosen for a cross-sectional, non-experimental research strategy, based on a telephone survey, using a structured questionnaire with direct questions as the method of data collection. The main limitation of a cross-sectional survey is that definite causal inferences cannot be drawn, despite the discussion about positive or negative effects between variables. Because a cross-sectional study is conducted at just one point in time, it is therefore also not suited for a study of possible change. These limitations then lead to some other research suggestions: to conduct a longitudinal study in service firms which changed its functional design into an organizational design with less division of labor and more responsible autonomy; or to conduct common cross-sectional surveys at two or more points in time, with a new sample on each occasion.

Apart from the usual data restrictions, one of the conceptual limitations is the use of a 7-point Likert scale. A certain amount of common method bias was probably not prevented, since many questions had this format. For practical reasons, the scales did not consist of many items - some of them came from existing scales and some of them were made especially for this study, where the choices may have been arbitrary. However, the reliability of most scales appeared to be acceptable. Whether the conclusions in this study are biased and limited can only be demonstrated by future research, using newer and better data. 


\section{REFERENCES}

Bakker, A. B. (2009). Building engagement in the workplace. In R. J. Burke \& C. L. Cooper (Eds.). The peak performance organization (pp. 50-72). Oxon, UK.

Bakker, A. B. (2010). Weekly work engagement and performance. A study among starting teachers. Journal of Occupational and Organizational Psychology, 83(1), 189-206.

Bakker. A. B., \& Demerouti, E. (2009). The crossover of work engagement between working couples: A closer look at the role of empathy. Journal of Managerial Psychology, 24(3), 220-236.

Bakker, A. B., Demerouti, E., \& Verbeke, W. (2004). Using the job demands-resources model to predict burnout and performance. Human Resource Management, 43(1), 83-104.

Blumberg, B. (2005). Business research methods. McGraw-Hill Education.

Cable, D. M., \& Parsons, C. K. (1997). Socialization tactics and person-organization fit. Personnel Psychology, 54(1), 1-23.

Davenport, T. (2002). Can you boost knowledge work's impact on the bottom line? Management Update, $7(11), 3-5$.

Davenport, T., \& Prusak, L. (2000). Working knowledge: How organizations manage what they know. Boston, MA: Harvard Business School Press.

de Haas, M. J. O. M. (2004). De professionele manager en de managing professional. Advocatenblad, 16, 708-710.

de Sitter, L. U. (2000). Synergetisch produceren. Van Gorcum.

de Sitter, L. U., den Hertog, J. F., \& Dankbaar, B. (1997). From complex organizations with simple jobs to simple organizations with complex jobs. Human Relations, 50(5), 497-534.

Drucker, P. (1999). Knowledge-worker productivity: The biggest challenge. California Management Review, 41(2), 79-94.

Dullaert, C. W. M., Griendt, \& van de, H. F. M. (2004). De lastige partner. Management van een advocatenkantoor.

Edwards, J. R. (1991). Person-job fit: A conceptual integration, literature review and methodological critique. International Review of Industrial and Organizational Psychology, 6, 283-357.

Eisenhardt K. M. (1991). Better stories and better constructs: The case for rigor and comparative logic. Academy of Management Review, 16(3), 620-627.

González-Romá, V., Schaufeli, W. B., Bakker, A. B., \& Lloret, S. (2006). Burnout and work engagement: independent factors or opposite poles? Journal of Vocational Behavior, 68(1), 165-174.

Haas, M. R., \& Hansen M. T. (2005). When using knowledge can hurt performance: The value of organizational capabilities in a management consulting company. Strategic Management Journal, 26(1), 1-24.

Hansen M. T., \& Haas M. R. (2001). Competing for attention in knowledge markets: Electronic document dissemination in a management consulting company. Administrative Science Quarterly, 46(1), 128.

Heskett, J., Sasser, E., \& Schlesinger L. (1997). The Service Profit Chain.

Jöreskog, K. G. (1996). Structural equation modeling with the SIMPLIS command language. Lincolnwood, IL: Scientific Software International.

Jöreskog, K. G., \& Sorbom, D. (1986). LISREL VI: Analysis of linear structural relationships by maximum likelihood, instrumental variables, and least squares methods. Mooresville, IN: Scientific Software.

Karasek, R. (2001). Toward a psychosocially healthy work environment: Broader roles for psychologists and sociologists. Washington, DC: APA Books.

Karasek, R. A., \& Theorell, T. (1990). Healthy work. New York, NY: Basic Books.

Kristof, A. L. (1996). Person-organization fit: An integrative review of its conceptualizations, measurement, and implications. Personnel Psychology, 49(1), 1-49. 
Kristof-Brown, A. L. Jansen, K. J., \& Colbert, A. E. (2002). A policy-capturing study of the simultaneous effects of fit with jobs, groups, and organizations. Journal of Applied Psychology, 87(5), 985993.

Kuipers, H., \& van Amelsvoort, P. (1990). Slagvaardig organiseren. Inleiding in de sociotechniek als integrale ontwerpleer. Kluwer.

Kuipers, H., van Amelsvoort, P., \& Kramer, E. (2010). Het nieuwe organiseren. Alternatieven voor de bureaucratie. Acco.

Mayson, S. (1997). Making sense of law firms. Strategy, structure \& ownership.

McEvily, S. K., Das, S., \& McCabe, K. (2000). Avoiding competence substitution through knowledge sharing. Academy of Management Review, 25(2), 294-312.

Pink, D. (2010). Drive, the surprising truth about what motivates us. New York: Canongate.

Podolny, J. M. (1994). Market uncertainty and the social character of economic exchange. Administrative Science Quarterly, 39(3), 458-483.

Salanova, M., Agut, S., \& Peiró, J. M. (2005). Linking organizational resources and work engagement to employee performance and customer loyalty: The mediation of service climate. Journal of Applied Psychology, 90(6), 1217-1227.

Schaufeli, W. B., \& Bakker, A. B. (2004). Job demands, job resources, and their relationship with burnout and engagement: A multi-sample study. Journal of Organizational Behavior, 25(3), 293-315.

Schaufeli, W. B., Salanova, M., González-Romá, V., \& Bakker, A. B. (2002). The measurement of engagement and burnout: A two sample confirmatory factor analytic approach. Journal of Happiness Studies, 3(1), 71-92.

Schaufeli, W. B., Taris, T. W., \& van Rhenen, W. (2008). Workaholism, burnout and work engagement: Three of a kind or three different kinds of employee well-being? Applied Psychology: An International Review, 57(2), 173-203.

Taris, R. (2003). Person-Environment Fit. A longitudinal study of the interaction between employee characteristics and work environmental characteristics. Ridderkerk.

Taylor, F.W. (1911) The Principles of Scientific Management.

van Amelsvoort, P. (1999). De moderne sociotechnische benadering. Een overzicht van de sociotechnische theorie.

Williams, T. (2005). Cooperation by design: Structure and cooperation in interorganizational networks. Journal of Business Research, 58(2), 223-231. 